\title{
The relationship between HBV serum markers and the clinicopathological characteristics of hepatitis B virus-associated glomerulonephritis (HBV-GN) in the northeastern chinese population
}

\author{
Lei Zhang ${ }^{\dagger}$, Hongxue Meng ${ }^{\dagger}$, Xingying Han, Changsong Han, Chuanhui Sun, Fei Ye and Xiaoming Jin ${ }^{*}$
}

\begin{abstract}
Background: To investigate the effect of HBV markers on HBV-GN.

Methods: The immunohistochemistry was used to detect HBsAg and $\mathrm{HBCAg}$ in frozen sections of renal biopsy, the changes in HBV serum markers, renal functional parameters and clinical manifestations or symptoms were observed to analyze renal damage.

Results: Using renal biopsy data from 329 cases, this study found that the most common pathological subtype in HBV-GN was mesangioproliferative glomerulonephritis (MsPGN) $(24.9 \%, P<0.05)$, and $29.4 \%$ of patients who show serological HBsAg, HBeAg and anti-HBC positive developed membranoproliferative glomerulonephritis (MPGN) $(P<0.05)$. The immunohistochemistry was used to detect HBsAg and HBcAg in frozen sections.50\% of $\mathrm{HBsAg}$ and $\mathrm{HBCAg}$ deposits was observed in the glomeruli of MPGN patients, while $36.6 \%$ of $\mathrm{HBsAg}$ and $43.9 \%$ of $\mathrm{HBCAg}$ deposited in the glomeruli of MsPGN patients. The deposits of HBsAg and HBCAg in glomeruli were directly correlated with IgA, IgG, IgM and C3 deposits. In addition, cases with a moderate to severe decrease as reflected by the glomerular filtration rate (GFR) were predominantly patients with MPGN $(31.6 \%, P<0.05)$ or MsPGN $(21.1 \%$, $P<0.05)$. Patients who were serological HBsAg, $\mathrm{HBeAg}$ and anti-HBc positive or $\mathrm{HBsAg}$, anti-HBe and anti-HBc positive mainly exhibited urine and renal parameter changes.
\end{abstract}

Conclusion: Examination of HBV markers in serum and renal biopsy will be useful for clinicians to predict the renal damage in early stage when it is reversible in HBV-GN.

Keywords: HBV serum markers, Pathological subtype of hepatitis B virus-associated glomerulonephritis, Renal functional parameters, Clinical manifestations or symptoms

\section{Background}

Hepatitis B virus (HBV) infection occurs worldwide, with a high prevalence in most developing countries in Southeast Asia and Africa. Extra-hepatic manifestations of HBV infection are being increasingly recognized, with an expanding prevalence. One of the most common manifestations is HBV-GN [1,2]. Different pathological types of glomerular lesions have been described in association with HBV infection, including pathological patterns such

\footnotetext{
*Correspondence: jinxm55@yahoo.com.cn

${ }^{\dagger}$ Equal contributors

Department of Pathology, Basic Medical Science College, Harbin Medical University, 157 Baojian Road, Nangang District, Harbin 150081, China
}

as MPGN, MsPGN, and Membranoproliferative glomerulonephritis (MN). MPGN is a chronic progressive glomerulonephritis that is common in young and middle-aged adults, and is characterized by an increase in mesangial cellularity and matrix, with thickening of glomerular capillary walls secondary to subendothelial and mesangial deposition of circulating immune complexes and/or complement factors, cellular entrapment, and new basement membrane formation. It is always present in nephrotic syndrome or acute nephritic syndrome [3]. MPGN has a poorer prognosis than $\mathrm{MN}$ and is associated with a high risk of renal failure. MsPGN is common in teenagers and demonstrates mesangial hypercellularity 
and/or increase in mesangial matrix [4]. Its clinical manifestation and prognosis of moderate-severe MsPGN are similar to those of MPGN. MN is a chronic progressive glomerulonephritis that is common in adults, characterized by sub-epithelial immune deposits inducing nonselective proteinuria. However, among these histological types, MN has been reported as the commonest pathological type of HBV-GN in Hong Kong and South Africa [5-7], compared to IgA nephropathy followed by MN in Thailand [8] and MN and MPGN in Japanese adults [9].

HBV infection is prevalent in China, and HBV-GN commonly causes renal damage secondary to HBV infection. At present, there are no definite diagnostic criteria for HBV-GN. However, the reference diagnostic criteria used in China are as follows [10]: a) HBsAg-positive serum; b) presence of glomerular nephritis, excluding lupus nephritis and other secondary glomerular diseases; and c) HBV antigens including HBsAg or HBcAg, or HBV DNA measured by PCR in nephridial tissue. Among these criteria, the third criterion is required for a final diagnosis. In our study, for serum HBsAg-positive patients, including $\mathrm{HBsAg-}$ - HBeAg- and anti-HBc-positive patients; HBsAg-, anti-HBe- and anti-HBc-positive patients; $\mathrm{HBsAg}$ - and anti-HBc-positive patients; and simple HBsAg-positive patients, it is of great clinical significance to analyse the degree of HBV antigen deposited in renal tissue and the glomerular impairment. These different serum markers of $\mathrm{HBV}$ are an indirectly measure of the injury and prognosis of HBV-GN. The present study summarised and analysed the changes in HBV serum markers, renal functional parameters, clinical manifestations or symptoms and the pathological data and of 329 clinical cases of HBV-GN from Harbin in northeastern China.

\section{Methods}

\section{The clinical data}

A total of 329 cases from among 5250 patients (329/5250, 6.27\%), who underwent renal biopsies and were diagnosed as HBV-GN with HBsAg-positive serum, were analysed in this study. Diagnoses were made by the Department of Pathology, Harbin Medical University, from January 1998 to April 2010. There were 221 males and 108 females, with a male-to-female ratio of 2.05:1. All patients were between 17 years old and 63 years old with, an average age of $33.28 \pm 9.45$ years. 3136 cases from 5250 patients (3136/5250, 59.7\%) with HBsAg-negative serum were taken as negative control. Negative control was selected and matched for gender and age distribution (average age of $33 \pm 14$ years and male-to-female ratio of 1.97:1).

\section{The pathological classification and the diagnosis criteria}

The lesions of the 329 cases of glomerular nephritis were classified according to the $1990 \mathrm{WHO}$ Classification criteria [11]. The diagnosis of nephropathy was confirmed by pathology. Sections from all biopsy specimens also were stained routinely with hematoxylin and eosin (H\&E), periodic acid-sliver methenamine (PASM), Masson's trichrome, and antibodies against IgA, IgG, IgM and the C3 complement component. Fluorescently labelled goat antihuman IgA (alpha) was purchased from KPL (Kirkegaard \& Perry Laboratories, Inc. US). FITC-labelled mouse antihuman IgG1 (Fc) and FITC-labelled goat anti-human IgM were purchased from Abcam Limited (Cambridgeshire, UK). FITC-labelled rabbit anti-human C3c antibody was purchased from Dako (Dako A/S, Glostrup, Denmark).

\section{$\mathrm{HBsAg}$ and HBcAg were detected in frozen and paraffin section with immunohistochemical method}

Frozen slices from biopsies of the 329 cases were kept in a low-temperature freezer. Monoclonal anti-human-HBsAg, anti-human-HBcAg and goat anti-mouse antibodies were purchased from Zhongshan Goldenbridge Biotechnology Co., Ltd. HBsAg and HBcAg were detected with immunohistochemical method in frozen and paraffin sections.

\section{The renal function staging, urine and renal parameters}

The renal function was staged as CKD I-V according to the American standard stages of renal function [12]. The staging is based on the degree to which glomerular filtration rate (GFR) is reduced. The value of the GFR was calculated, adjusting for the creatinine level, age and body weight. The higher the level of GFR was, the more effectivity for the kidney can remove toxins. The GFR was divided into five categories: I: normal or increased GFR with renal damage, GFR > 90; II: mild decrease in the GFR with renal damage, GFR: 60-89; III: moderate decrease in the GFR, GFR: 30-59; IV: severe decrease in the GFR, GFR: 15-29; and V: renal failure, GFR $<15$ or dialysis. Changes in routinely determined urine and

\section{Table 1 Histological diagnosis of HBV-positive patients} ( $\mathrm{N}=329)$

\begin{tabular}{lll}
\hline $\begin{array}{l}\text { Histological } \\
\text { diagnosis }\end{array}$ & $\begin{array}{l}\text { HBsAg positive in } \\
\text { serum Number (\%) }\end{array}$ & $\begin{array}{l}\text { HBsAg negative in } \\
\text { serum Number (\%) }\end{array}$ \\
\hline MsPGN & $82\left(24.9^{*}\right)$ & $476(15.2)$ \\
MPGN & $64(19.5)$ & $254(8.1)$ \\
MN & $38(11.6)$ & $650(20.7)$ \\
MCG & $31(9.4)$ & $296(9.4)$ \\
GML & $30(9.1)$ & $501(16.0)$ \\
IgAN & $51(15.5)$ & $669(21.3)$ \\
other & $33(10)$ & $290(9.24)$ \\
Total & 329 & 3136 \\
\hline
\end{tabular}

\section{${ }^{*} \mathrm{P}<0.05$.}

Abbreviations: MsPGN, Mesangioproliferative glomerulonephritis; MPGN, Membranoproliferative glomerulonephritis; MN, Membranous Nephropathy; MCG, Minimal change glomerulopathy; GML, Glomerular minor lesion; IgAN, $\lg$ A Nephropathy. 
Table 2 Clinical significance of HBV-positive patient serum $(N=329)$

\begin{tabular}{|c|c|c|c|c|c|c|}
\hline \multicolumn{5}{|c|}{ HBV-infectious markers in serum } & \multirow[t]{2}{*}{ Number (\%) } & \multirow[t]{2}{*}{ Clinical significance } \\
\hline HBsAg & HBsAb & $\mathrm{HBeAg}$ & $\mathrm{HBeAb}$ & $\mathrm{HBCAb}$ & & \\
\hline+ & - & + & - & + & $160(48.6) *$ & acute, chronic type B hepatitis, highly contagious \\
\hline+ & - & - & + & + & $89(27.1) *$ & acute, chronic type B hepatitis, contagious \\
\hline+ & - & - & - & + & $47(14.3)$ & acute, chronic type B hepatitis, contagious \\
\hline+ & - & - & - & - & $33(10)$ & acute infection, incubation at a later period \\
\hline
\end{tabular}

renal parameters including the urine protein, blood urea nitrogen (BUN) and serum creatinine $(\mathrm{Scr})$ levels were documented. The concentration of protein in the urine was quantitatively detected using the sulphosalicylic acid method. The level of urine protein was graded semiquantitatively on a negative to $4+$ scales. The serum HBV markers and pathological subtypes of patients with high BUN and Scr levels were analysed.

Ethics approval was obtained from the ethical committee of Harbin Medical University, China.

\section{Statistical analysis}

Statistical analysis was performed using SAS version 9.1 software (SAS Institute Inc., Cary, NC, USA). Comparisons of categorical data were performed using the chi-square test, with $P<0.05$ being considered statistically significant.

\section{Results}

The relationship between different serum markers for $\mathrm{HBV}$ in 329 cases and the clinical and pathological typing of HBV-GN

Among the 329 cases of HBV-GN, there were many types of primary glomerulonephritis; however, MsPGN was the most common type $(82 / 329,24.9 \%, P<0.05)$. The second most common type of HBV-GN was MPGN (64/329, 19.5\%) followed by IgA nephropathy (IgAN). But IgAN (669/3136, 21.3\%), MN (650/3136, 20.7\%), GML (501/3136, 16\%) and MsPGN (470/3136, 15.2\%) were the major types in the negative control (Table 1 ).

Different HBV-infection markers in serum are used to judge the severity of an infection and reflect the replication of $\mathrm{HBV}$ in clinical practice (Table 2). The frequency of the detection of $\mathrm{HBsAg}, \mathrm{HBeAg}$ and anti-HBc positivity was $48.6 \%(P<0.05)$, and $27.1 \%$ of the 329 cases were $\mathrm{HBsAg}$, anti-HBe and anti-HBc positive $(P<0.05)$. These results indicate that the damage to the glomeruli was severe when patients had serious HBV infections.

The most common pathological type of patients positive for HBsAg, HBeAg and anti-HBc was MPGN (47/160, $29.4 \%, P<0.05)$; MsPGN was observed in patients who were $\mathrm{HBsAg}, \mathrm{HBeAg}$ and anti-HBc positive and in those who were $\mathrm{HBsAg}$, anti-HBe and anti-HBc positive 37/160 (23.1\%, $P<0.05)$; and 26/89 (29.2\%, $P<0.05)$, respectively (Table 3, Figure 1).

The characteristics of $\mathrm{HBsAg}$ and $\mathrm{HBCAg}$ deposits in the glomeruli of patients with HBV-GN

HBsAg and $\mathrm{HBcAg}$ were detected in frozen renal biopsy sections from the 329 cases of HBV-GN. HBsAg and $\mathrm{HBcAg}$ were deposited in the mesangial region and in the capillary walls of glomeruli (Figures 2C, D, E, F) but not in renal tubules or in the interstitium. However, in paraffin-embedded sections, weak expression of $\mathrm{HBsAg}$ and $\mathrm{HBcAg}$ was detected mostly in the proximal convoluted tubules of glomeruli, data not shown. The present study was thus focused on the immunohistochemistry of the frozen slices. The results from the frozen sections showed a $50 \%$ expression rate of $\mathrm{HBsAg}$ and $\mathrm{HBcAg}$ in the glomeruli of patients with MPGN $(P<0.05)$ and $36.6 \%$ and $43.9 \%$ expression rates, respectively, for MsPGN $(P<0.05)$ (Table 4$)$.

The relationship between the serum HBV-infection markers, age, initial symptoms, changes in routine urine and renal parameters and the stage of renal function in the 329 patients with HBV-GN.

Table 3 The relationship between serum HBV-infectious markers in 329 cases and the pathological subtype of HBV-GN

\begin{tabular}{|c|c|c|c|c|c|c|c|c|}
\hline \multirow{2}{*}{$\begin{array}{l}\text { HBV-infectious } \\
\text { markers in serum }\end{array}$} & \multirow[t]{2}{*}{$\mathbf{N}$} & \multicolumn{7}{|c|}{ The pathological subtype of HBV-GN, number (\%) } \\
\hline & & MsPGN & MPGN & MN & MCG & GML & $\lg A N$ & Other \\
\hline $\mathrm{HBsAg}+, \mathrm{HBeAg}+, \mathrm{HBCAb}+$ & 160 & $37(23.1) *$ & $47(29.4) *$ & $16(10)$ & $9(5.6)$ & $13(8.1)$ & 23(14.4) & $15(9.4)$ \\
\hline $\mathrm{HBsAg}+, \mathrm{HBeAb}+, \mathrm{HBCAb}+$ & 89 & $26(29.2) *$ & $10(11.2)$ & $9(10.1)$ & $8(9)$ & $11(12.4)$ & $16(18)$ & $9(10.1)$ \\
\hline $\mathrm{HBsAg}+, \mathrm{HBCAb+}$ & 47 & $11(23.4)$ & $4(8.5)$ & $9(19.2)$ & $6(12.8)$ & $1(2.1)$ & $9(19.2)$ & $7(14.9)$ \\
\hline $\mathrm{HBsAg}+$ & 33 & $8(24.2)$ & $3(9.1)$ & $4(12.1)$ & $8(24.2)$ & $5(15.2)$ & $3(9.1)$ & $2(6.1)$ \\
\hline
\end{tabular}

*P $<0.05$. 


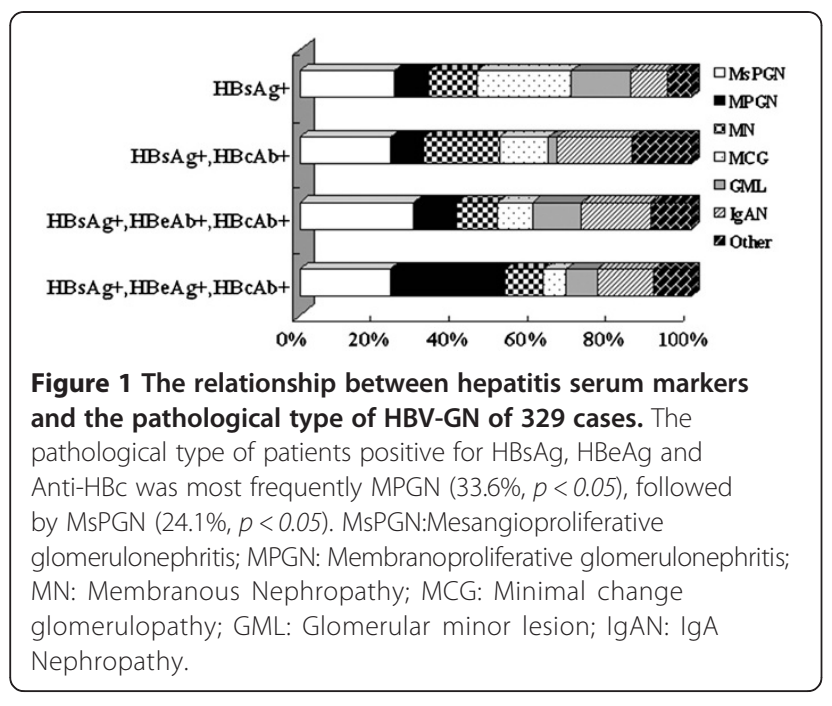

Patients aged from 20 to 49 years had the highest incidence of HBV-GN, with a peak at 30 to 40 years (Figure 3A). The most common initial symptom was edema (Figure 3B). Past medical history included hepatitis lasting from several months to several decades.
The relationship between the serum HBV infection markers of 329 cases and the staging of renal function revealed that most patients were in stage I. The percentage of patients with glomerular damage resulting from HBV infection was $68.4 \%$ (225/329) among stage I patients. In addition, a moderate-severe decrease in the GFR (including stages III,IVand V)to renal function failure was observed in $11.6 \%(38 / 329)$ (Tables 5, 6, Figure 4); however, among the 38 cases, the pathological type was MPGN in 12 cases $(12 / 38,31.6 \%$, $P<0.05)$ and MsPGN in 8 cases $(8 / 38,21.1 \%, P<0.05)$. Together, patients with MPGN and MsPGN (20/38, $52.6 \%, P<0.05)$ were at a high risk of renal failure, with an unfavourable prognosis (Table 7). The quantitative detection of urine protein revealed that renal function was easily damaged in patients with MPGN and MsPGN (Figure 5A), and patients with $\mathrm{HBsAg-}$-, $\mathrm{HBeAg}$ - and anti-HBc-positive serum or HBsAg-, anti$\mathrm{HBe}-$ and anti-HBc-positive serum were likely to have high levels of protein in the urine (Figure 5B). The most common pathological subtypes of patients with elevated BUN and Scr levels were MsPGN and MPGN (Figure 5C, $P<0.05$ ).
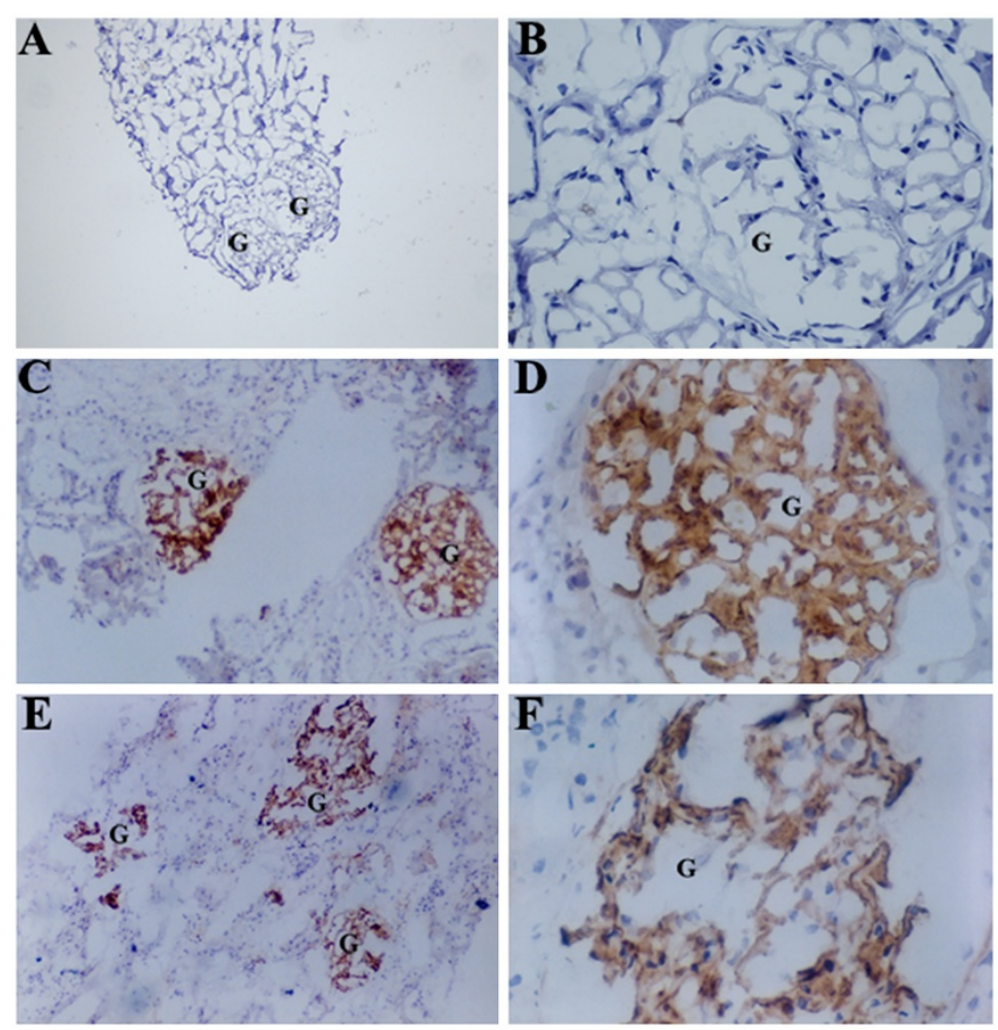

Figure 2 The $\mathbf{H B s A g}$ and $\mathbf{H B c A g}$ levels in glomeruli in frozen biopsy slices. $2 \mathbf{A}, 2 \mathbf{B}$ (the magnification of $2 \mathbf{A}$ ): HBsAg was not present in the glomerulus and tublules in glomeruli of HBsAg-negetive cases (G indicates a glomerulus). SP $\times 120$ and SP $\times 4602 \mathbf{C}, 2 \mathbf{D}$ (the magnification of $2 \mathbf{C}$ ): $\mathrm{HBsAg}$ present in glomeruli. SP $\times 120$ and $\mathrm{SP} \times 460.2 \mathbf{E}, 2 \mathbf{F}$ (the magnification of $2 \mathrm{E}$ ): HBCAg present in the glomeruli. SP $\times 120$ and $\mathrm{SP} \times 460$. 
Table 4 The expression of HBsAg and HBcAg in glomeruli from different pathological subtypes of HBV-GN

\begin{tabular}{|c|c|c|c|c|c|}
\hline \multirow[t]{2}{*}{ The pathological subtype } & \multirow[t]{2}{*}{ Number } & \multicolumn{2}{|c|}{ HBsAg number (\%) } & \multicolumn{2}{|c|}{ HBcAb number (\%) } \\
\hline & & + & - & + & - \\
\hline MsPGN & 82 & $30(36.6)^{*}$ & $52(63.4)$ & $36(43.9)^{*}$ & $46(56.1)$ \\
\hline MPGN & 64 & $32(50)^{*}$ & $32(50)$ & $32(50)^{*}$ & $32(50)$ \\
\hline MN & 38 & 14(36.8) & $24(63.2)$ & $23(60.5)$ & $15(39.5)$ \\
\hline MCG & 31 & $22(71)$ & $9(29)$ & $16(51.6)$ & $15(48.4)$ \\
\hline GML & 30 & $12(40)$ & $18(60)$ & 13(43.3) & $17(56.7)$ \\
\hline $\lg A N$ & 51 & $12(23.5)$ & $39(76.5)$ & $12(23.5)$ & $39(76.5)$ \\
\hline other & 33 & $14(42.4)$ & 19(57.6) & 11(33.3) & $22(66.7)$ \\
\hline total & 329 & 136(41.3) & 193(58.7) & $143(43.5)$ & $186(56.5)$ \\
\hline
\end{tabular}

${ }^{*} \mathrm{P}<0.05$.

The relationship between HBV antigen deposits in glomeruli and the types of Ig and complement deposits HBsAg and $\mathrm{HBcAg}$ were deposited in the glomeruli of patients with HBV-GN along with the following Ig types and the following complement components. IgA deposition reached $73 \%(89 / 122)$, C3 deposition reached 68.9\% (84/122), IgG deposition reached 78.7\% (96/122), and IgM deposition reached $47.5 \%$ (58/122). The frequency of IgA deposition in patients with HBV-GN was highest in those who only expressed $\mathrm{HBcAg}$ in glomeruli $(49 / 64,76.6 \%)$, but this difference was not statistically significant (Table 8).

\section{Discussion}

Chronic hepatitis $\mathrm{B}$ and asymptomatic carriage of $\mathrm{HBV}$ is associated with HBV-GN [13]. Patients with HBV-GN have a high morbidity rate. In general, the clinical manifestations are not specific, and the hepatic and renal functions are normal for several years. The initial symptoms detected in medical examinations are usually proteinuria and hematuria. By this time, the renal damage is severe and irreversible. Important laboratory examinations include the evaluation of serum HBV markers, changes in renal hemodynamics and a pathological examination including a renal biopsy. These examinations are important for early diagnosis and treatment.
Some studies have investigated the relationship between HBV infection and IgA nephropathy. Lai et al. found that the morbidity due to IgA nephropathy was high in an area of high HBV prevalence. The frequency of HBsAg-positivity in IgAN serum was higher than that in healthy control serum. HBsAg, $\mathrm{HBcAg}$ and the corresponding immune complexes were deposited in the glomeruli. Furthermore, the deposit site was the same as that of IgA. This finding is notable because HBV and its immune complexes deposited in the glomeruli play a major role in the pathogenesis of IgAN [14]. The above mentioned studies give a hint at the close relationship between HBV infection and renal damage. HBV can involve the kidney as well as the liver, and renal function must thus be monitored in HBV-infected patients [15]. Thus, when the damage of $\mathrm{HBV}$ is evaluated, doctors need to focus on the change in hepatic function and to monitor the renal function index. The renal damage is related to virus replication and, more importantly, is linked to the immune response [16]. Chronic HBV infection can induce renal damage, and antigen-antibody immune complexes against $\mathrm{HBs}, \mathrm{HBc}$, or $\mathrm{HBe}$ together with complement components have been demonstrated to induce renal damage [17].

In the present study, the detection of HBsAg and $\mathrm{HBcAg}$ along with the expression of Ig types and the
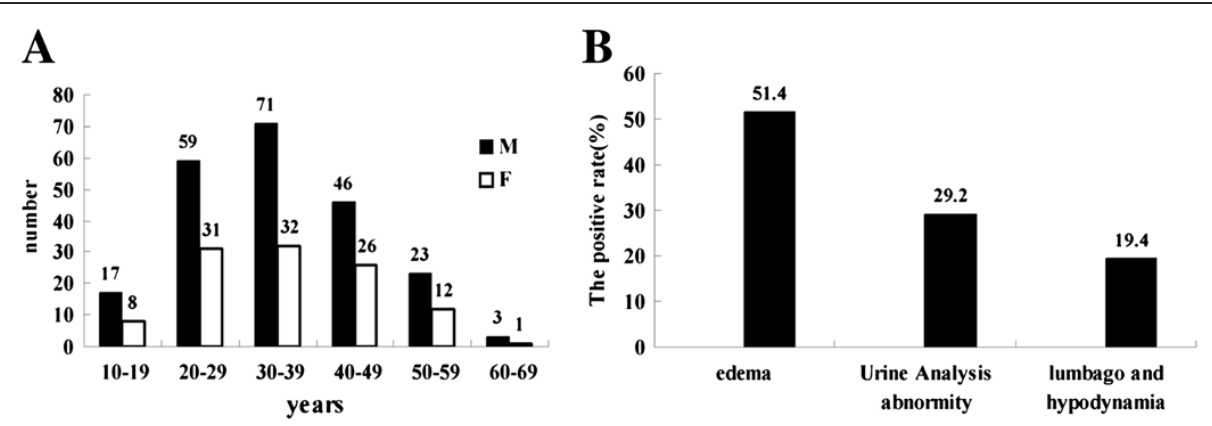

Figure 3 Ages and initial symptoms of the 329 patients with HBV-GN. 3A: Age distribution of the 329 cases of HBV-GN. 3B: Initial symptoms of the 329 cases of HBV-GN. 
Table 5 The relationship between serum HBV-infectious markers in 329 cases, and initial symptoms and the staging of renal function in HBV-GN

\begin{tabular}{|c|c|c|c|c|c|c|c|c|c|}
\hline \multirow{2}{*}{$\begin{array}{l}\text { HBV-infectious } \\
\text { markers in serum }\end{array}$} & \multirow[b]{2}{*}{$\mathbf{N}$} & \multicolumn{3}{|c|}{ Initial symptoms number (\%) } & \multicolumn{5}{|c|}{ Renal function staging, number(\%) } \\
\hline & & Edema & Urine abnormity & Lumbago and hypodynamia & 1 & II & III & IV & v \\
\hline $\mathrm{HBsAg}+, \mathrm{HBeAg}+, \mathrm{HBcAb}+$ & 160 & $84(52.5)$ & 49(30.6) & $27(16.9)$ & $110(68.8)$ & $35(21.9)$ & $12(7.5)$ & $2(1.3)$ & $1(0.6)$ \\
\hline $\mathrm{HBsAg}+, \mathrm{HBeAb}+, \mathrm{HBcAb}+$ & 89 & $45(50.6)$ & $26(29.2)$ & 18(20.2) & $61(68.5)$ & $15(16.9)$ & $6(6.7)$ & $3(3.4)$ & $4(4.5)$ \\
\hline $\mathrm{HBsAg}+, \mathrm{HBcAb}+$ & 47 & 24(51.1) & $11(23.4)$ & $12(25.5)$ & $27(57.5)$ & $13(27.7)$ & $3(6.4)$ & $4(8.5)$ & 0 \\
\hline $\mathrm{HBsAg}+$ & 33 & $16(48.5)$ & 10(30.3) & $7(21.2)$ & $27(81.8)$ & $3(9.1)$ & $2(6.1)$ & $1(3)$ & 0 \\
\hline Total & 329 & $169(51.4)$ & $96(29.2)$ & $64(19.5)$ & $225(68.4)$ & $66(20.1)$ & $23(7)$ & 10(3) & $5(1.5)$ \\
\hline
\end{tabular}

presence of complement components in the glomerular deposits suggests that an immune complex mechanism leads to glomerular injury. The antigen-antibody complex in renal tissues is mainly derived from blood circulation, and the circulating immune complex is detained passively in the glomeruli. The immune complex damages the kidney by activating the complement system and cytokines, which is one of the major mechanisms of the pathogenesis of HBV-GN. Jiang W [18] suggested that these autoimmunity factors may play a role in the morbidity of HBV-GN. HBcAg in renal tissue as a target antigen can initiate cytotoxic T-cell-linked immunologic injury in renal tubular epithelial cells. The pathogenesis of HBV-GN is closely related to the immune state in human, and the damage of cells after $\mathrm{HBV}$ infection is provoked by the immune response in the host. If a patient's immune system is inadequate, the virus cannot be eliminated. In this state, the illness can be delayed for several years, contributing to the pathogenesis of HBV-GN.

The present study revealed that the degree of glomeruli damage was different in patients with different serum HBV infection markers. The serum HBV infection markers were predominantly $\mathrm{HBsAg}, \mathrm{HBeAg}$ and anti-HBc and $\mathrm{HBsAg}$, anti-HBe and anti-HBc, which were related to the severity of urine protein leakage.

The pathological type of HBV-GN as determined by renal biopsy was most frequently MsPGN, followed by MPGN. The pathological subtypes of patients with elevated BUN and Scr levels were MsPGN and MPGN. This result was different from that of previous studies that have shown that the most common histological type was MN [5-9]. The reported prevalence of HBV-GN closely

Table 6 The relationship between GFR and renal function staging

\begin{tabular}{lcc}
\hline Stage & GFR & Number(\%) \\
\hline I & $>90$ & $225(68.4)$ \\
II & $60-89$ & $66(20.1)$ \\
III & $30-59$ & $23(7)$ \\
IV & $15-29$ & $10(3)$ \\
V & $<15$ & $5(1.5)$ \\
\hline
\end{tabular}

parallels the geographic patterns of HBV prevalence, with marked differences in the epidemiology of HBV infection among continents and regions. Lu et al. reported that HBV S gene mutations were closely associated with HBV-GN. However, HBV serotype or genotype characteristics differ between areas; the serotype ayw and genotype A of HBV are predominant in HBV-GN in South Africa, while the endemic HBV strains are serotype adw and genotype $\mathrm{B}$ in south China, and serotype adr and genotype $C$ in Korea [19]. However, the effects of these differences on the pathological subtype composition and syndrome of HBV-GN remains unclear. There have been no further worldwide reports of HBV-GN since the report by Levy and Chen [20] in the 1980s, until now. The current data based on over one hundred million people in Northeast China will provide a useful basis for further investigations into HBV-GN.

HBsAg and HBcAg were deposited in the glomeruli of $50 \%$ of the patients with the MsPGN subtype of HBV$\mathrm{GN}$, and HBsAg and $\mathrm{HBcAg}$ were deposited in the

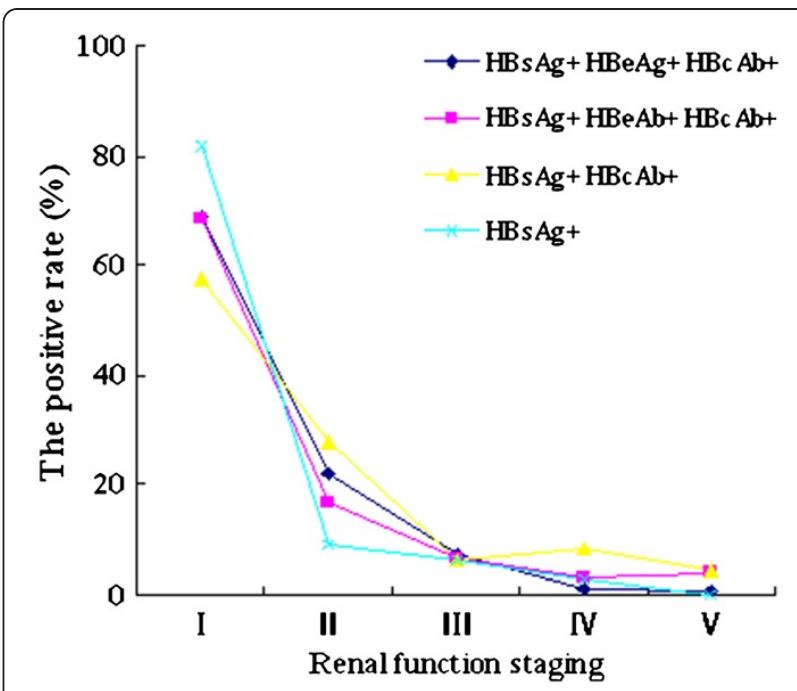

Figure 4 The relationship between the renal function stage and hepatitis serum markers in the $\mathbf{3 2 9}$ cases. The staging of renal function revealed that most patients were in stage I. The proportions of patients with glomerulus damage resulting from HBV infection were $68.39 \%(225 / 329)$ in stage I. 
Table 7 Moderate-severe decrease of GFR and the pathological subtype of HBV-GN

\begin{tabular}{lcccc}
\hline Pathological subtype & \multicolumn{4}{c}{ Renal function staging, number (\%) } \\
\cline { 2 - 5 } & III & IV & V & Total \\
\hline MsPGN & 6 & 2 & 0 & $8(21.1)^{*}$ \\
MPGN & 6 & 5 & 1 & $12(31.6)^{*}$ \\
MN & 0 & 1 & 0 & 1 \\
MCG & 0 & 0 & 1 & 1 \\
GML & 2 & 0 & 1 & 3 \\
IgAN & 3 & 1 & 0 & 4 \\
other & 6 & 1 & 2 & 9 \\
total & 23 & 10 & 5 & 38 \\
\hline
\end{tabular}

glomeruli in the MPGN patients of $36.6 \%$ and $43.9 \%$, respectively. With respect to the renal function staging of the 329 cases, most patients with HBV-GN were in stage I (68.3\%), and this condition was ignored by patients or doctors. Once the GFR has changed substantially, the kidneys have been irreversibly damaged. Thus, the detection of $\mathrm{HBsAg}$ and $\mathrm{HBcAg}$ in glomeruli of patients with HBV infection can predict the severity of the disease.

In general, the prognosis mainly depends on the pathological subtype. In this study, the prognosis of HBV-GN ranged from spontaneous remission to renal failure. The MPGN and MsPGN subtypes of HBV-GN represented over half $(52.7 \%)$ of the 38 cases in GFR stages III-V. Patients with the minimal glomerulonephritis subtype of
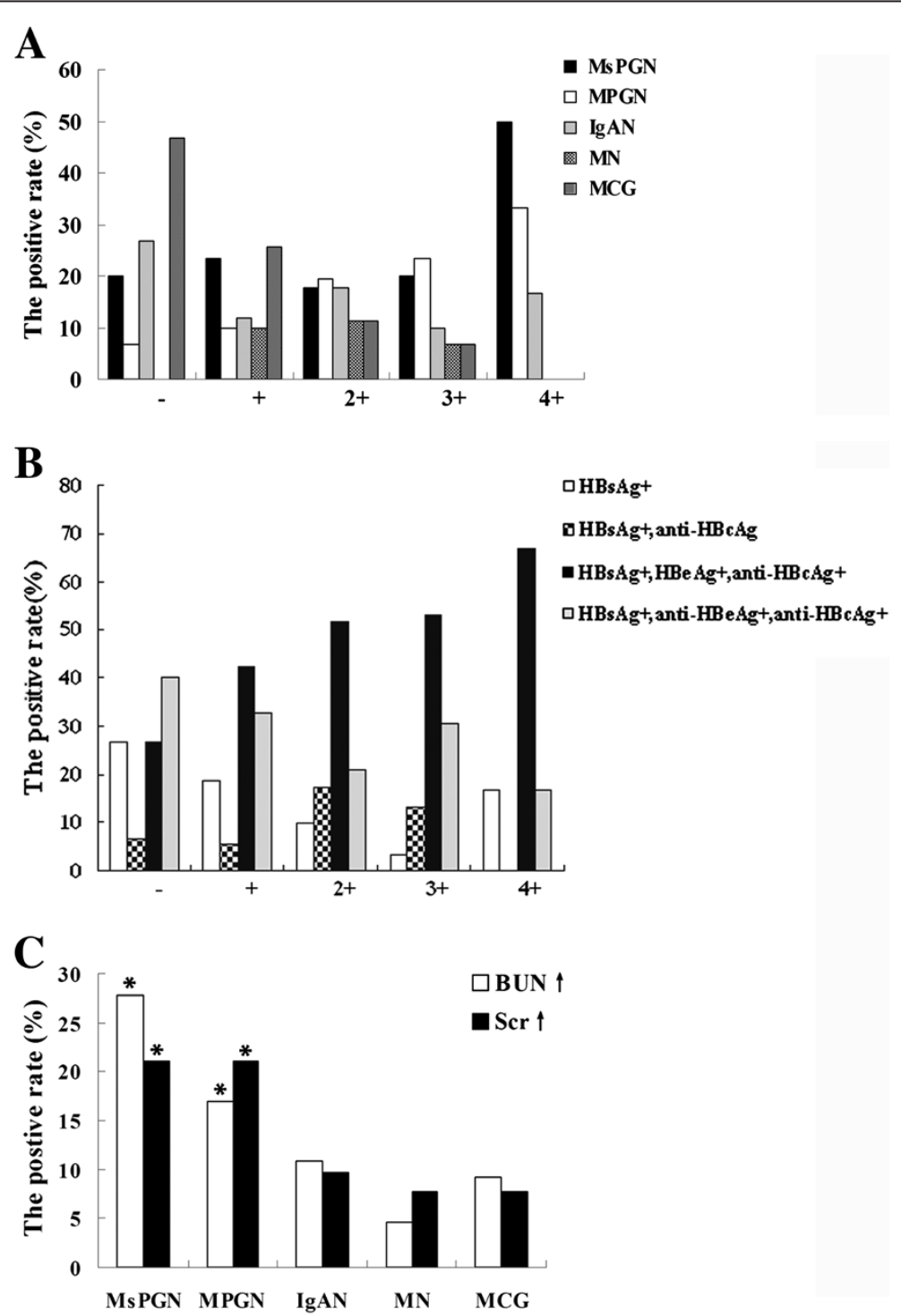

Figure 5 The distribution of different pathological subtype with different urine protein and elevated BUN and Scr. $5 \mathrm{~A}$ : In the quantitatively detection of urine protein, renal function were easily damaged in patients with MPGN and MsPGN; $5 \mathbf{B}$ : Patients with HBsAg, HBeAg and Anti-HBC positive and $\mathrm{HBsAg}$, Anti-HBe and Anti-HBC positive in serum were prone to leak out urine protein. $5 \mathrm{C}$ : The pathological subtype of patients with elevated BUN and Scr were MSPGN and MPGN $\left({ }^{*} P<0.05\right)$. 
Table 8 The relationship between the HBV expression and deposit of $\lg A, \lg M$, C3, $\lg G$

\begin{tabular}{llllll}
\hline $\begin{array}{l}\text { HBsAg and HBcAg } \\
\text { in renal tissue }\end{array}$ & N & $\begin{array}{l}\text { IgA positive } \\
\text { number (\%) }\end{array}$ & $\begin{array}{l}\text { C3 positive } \\
\text { number (\%) }\end{array}$ & $\begin{array}{l}\text { IgG positive } \\
\text { number (\%) }\end{array}$ & $\begin{array}{l}\text { IgM positive } \\
\text { number (\%) }\end{array}$ \\
\hline $\mathrm{HBSAg}+, \mathrm{HBCAg}-$ & 49 & $29(59.2)$ & $29(59.2)$ & $26(53.1)$ & $22(44.9)$ \\
$\mathrm{HBsAg}-, \mathrm{HBCAg}+$ & 64 & $49(76.6)$ & $44(68.8)$ & $42(65.6)$ & $22(34.4)$ \\
$\mathrm{HBSAg}+, \mathrm{HBCAg}+$ & 122 & $89(73)$ & $84(68.9)$ & $96(78.7)$ & $58(47.5)$ \\
$\mathrm{HBsAg}-, \mathrm{HBCAg}-$ & 94 & $64(68.1)$ & $64(68.1)$ & $67(71.3)$ & $43(45.7)$ \\
Total & 329 & 231 & 221 & 231 & 145 \\
\hline
\end{tabular}

HBV-GN experience slow disease progression with a benign prognosis; those patients with the MsPGN subtype have a poor prognosis, and those with the MPGN subtype have the worst prognosis. Patients with MsPGN and MPGN can advance to chronic renal function failure.

Most patients with HBV-GN were male. Patients aged from 30 to 39 years old had the highest incidence of HBV-GN. Their initial symptom was edema, in agreement with another study [13]. The deposits of HBsAg, $\mathrm{HBcAg}$, and simple $\mathrm{HBcAg}$ increased with the increase in the levels of deposits of IgA, IgG, IgM and C3 in the glomeruli. At present, the process from the onset and aggravation of $\mathrm{HBV}-\mathrm{GN}$ to renal function failure is closely related to the quantity of $\mathrm{HBsAg}, \mathrm{HbcAg}$, immune globulin deposits and the pathological subtype.

\section{Conclusion}

The study found that the most common pathological subtype in HBV-GN was MsPGN, and serological HBsAg-, $\mathrm{HBeAg}$ - and anti-HBc-positive patients was easy to develop MPGN. HBsAg and HBcAg were mainly deposited in the glomeruli of MsPGN and MPGN patients. In addition, cases with a moderate to severe decrease in the GFR were predominantly patients with MPGN or MsPGN. Patients who were serological HBsAg, HBeAg and anti-HBc positive or $\mathrm{HBsAg}$, anti-HBe and anti-HBc positive mostly exhibited urine and renal parameter changes. Thus, clinicians should use HBV markers to judge renal disease in the early stages when it is reversible.

\section{Abbreviations}

HBV-GN: Hepatitis B virus-associated glomerulonephritis; MsPGN: Mesangioproliferative glomerulonephritis; MPGN: Membranoproliferative glomerulonephritis; MN: Membranous nephropathy; MCG: Minimal change glomerulopathy; GML: Glomerular minor lesion; IgAN: IgA Nephropathy; GFR: Glomerular filtration rate; BUN: Blood urea nitrogen; Scr: Serum creatinine; H\&E: Hematoxylin and eosin; PASM: Periodic acid-sliver methenamine.

\section{Competing interests}

The authors declare that they have no competing interests.

\section{Authors' contribution}

$\mathrm{LZ}$ and HM contributed equally to this work. XH carried out the immunochemical studies. HM performed the statistical analysis. LZ summarized the data and wrote the article. $X J$ designed the whole experiment and submitted the article. $\mathrm{CH}, \mathrm{CS}$ and FY gathered the clinical data. All authors read and approved the final manuscript.

\section{Acknowledgements}

This work was supported by Harbin special fund for technological innovation (2006RFXXS035, 2007RFLXS017) and The Innovation Foundation of Harbin Medical University.

Received: 9 October 2011 Accepted: 13 September 2012

Published: 14 September 2012

\section{References}

1. Ayodele OE, Salako BL, Kadiri S, Arije A, Alebiosu CO: Hepatitis B virus infection: implications in chronic kidney disease, dialysis and transplantation. Afr J Med Sci 2006, 35:111-119.

2. Bhimma R, Coovadia HM, Adhikari M: Hepatitis B virus-associated nephropathy in black South African children. Pediatr Nephrol 1998, 12:479-484.

3. Waikhom R, Sarkar D, Patil K, Pandey R, Dasgupta S, Jadhav J, Abraham A: Non-IgA mesangioproliferative glomerulonephritis: a benign entity. Nephrol Dial Transplant 2012, 27:2322-2327.

4. Alchi B, Jayne D: Membranoproliferative glomerulonephritis. Pediatr Nephrol 2010, 25:1409-1418.

5. Lai KN, Lai FM: Clinical features and the natural course of hepatitis B virus-related glomerulopathy in adults. Kidney Int Supp/ 1991, 35:S40-45.

6. Lai KN, Li PK, Lui SF, Au TC, Tam JS, Tong KL, Lai FM: Membranous nephropathy related to hepatitis B virus in adults. N Engl J Med 1991, 324:1457-1463.

7. Bhimma R, Coovadia HM: Hepatitis B virus-associated nephropathy. Am J Nephrol 2004, 24:198-211.

8. Panomsak S, Lewsuwan S, Eiam-Ong S, Kanjanabuch T: Hepatitis-B virus-associated nephropathies in adults: a clinical study in Thailand. J Med Assoc Thai 2006, 89(Suppl 2):S151-156.

9. Tadokoro M: The clinico-pathological studies of hepatitis B virus nephropathy in adults. Nippon Jinzo Gakkai Shi 1991, 33:257-266.

10. Editorial committee of CHINESE JOURNAL OF INTERNAL MEDICINE: A summary of the discussion meeting of hepatitis B virus(HBV)-associated glomerulonephritis. CHINESE JOURNAL OF INTERNAL MEDICINE 1990, 29:519-521. In Chinese, Abstract in English.

11. Lee HS, Choi Y, Yu SH, Koh HI, Kim MJ, Ko KW: A renal biopsy study of hepatitis B virus-associated nephropathy in Korea. Kidney Int 1988, 34:537-543.

12. National Kidney Foundation: $\mathrm{K} / \mathrm{DOQ}$ clinical practice guidelines for chronic kidney disease: evaluation, classification, and stratification. Am J Kidney Dis 2002, 39:S1-266.

13. Johnson RJ, Couser WG: Hepatitis B infection and renal disease: Clinical, immunopathogenetic and therapeutic considerations. Kidney Int 1990, 37:663-676.

14. Lai KN, Lai FM, Tam JS, Vallance-Owen J: Strong associated between IgA nephropathy and hepatitis B surface antigenernia in endernic areas. Clin Nephrol 1998, 29:229-234.

15. Mason A: Role of viral replication in extrahepatic syndromes related to hepatitis B virus infection. Minerva Gastroenterol Dietol 2006, 52:53-66.

16. Lin CY, Lin CC, Chang GJ, King CC: Defect of cell-mediated immune response against hepatitis $B$ virus: an indication for pathogenesis of hepatitis-B-virus-associated membranous nephropathy. Nephron 1997, 76:176-185.

17. Li L, Li LS, Chen HP, Zhou HZ, Ji DX, Tang Z, Yu YS, Bai XY, Zhou H, Zhang $\mathrm{JH}$ : Primary glomerulonephritis in China. Analysis of 1001 cases. Chin Med $J$ (Engl) 1989, 102:159-164. 
18. Jiang W, Liu LQ: Effect of content of hepatitis $B$ virus DNA in the serum on the pathologic change in hepatitis $B$ virus associatedglomerulonephritis. Zhong Nan Da Xue Xue Bao Yi Xue Ban 2008, 33:857-860. In Chinese, Abstract in English.

19. Lu HZ, Zhu H, Zhou JH: S gene mutations of HBV in children with HBV-associated glomerulonephritis. Virol J 2012, 9:59.

20. Levy M, Chen N: Worldwide perspective of hepatitis B-associated glomerulonephritis in the 80s. Kidney Int 1991, 40:24-33.

doi:10.1186/1743-422X-9-200

Cite this article as: Zhang et al:: The relationship between HBV serum markers and the clinicopathological characteristics of hepatitis B virus-associated glomerulonephritis (HBV-GN) in the northeastern chinese population. Virology Journal 2012 9:200.

\section{Submit your next manuscript to BioMed Central and take full advantage of:}

- Convenient online submission

- Thorough peer review

- No space constraints or color figure charges

- Immediate publication on acceptance

- Inclusion in PubMed, CAS, Scopus and Google Scholar

- Research which is freely available for redistribution 